\title{
Study on the Changes and Correlation of Related Immune Factors before and after Chemotherapy in Non-Small Cell Lung Cancer
}

\author{
Jingjing Zhang1, Dianbin Song², Yi Dong1, Lu Bai', Dongqi Gao', Shenglin Zhang1, Yan Guo, \\ Fubo Li ${ }^{1}$, Xiaolei Yu${ }^{1}$, Qingshan Li ${ }^{*}$
}

\author{
${ }^{1}$ Department of Oncology, The Affiliated Hospital of Chengde Medical University, Chengde, China \\ ${ }^{2}$ Department of Urology, The Affiliated Hospital of Chengde Medical University, Chengde, China \\ Email: *songdianbin123@163.com
}

How to cite this paper: Zhang, J.J., Song, D.B., Dong, Y., Bai, L., Gao, D.Q., Zhang, S.L., Guo, Y., Li, F.B., Yu, X.L. and Li, Q.S. (2022) Study on the Changes and Correlation of Related Immune Factors before and after Chemotherapy in Non-Small Cell Lung Cancer. International Journal of Clinical Medicine, 13, 50-56.

https://doi.org/10.4236/ijcm.2022.131004

Received: December 20, 2021

Accepted: January 16, 2022

Published: January 19, 2022

Copyright $\odot 2022$ by author(s) and Scientific Research Publishing Inc. This work is licensed under the Creative Commons Attribution International License (CC BY 4.0).

http://creativecommons.org/licenses/by/4.0/

\section{(c) (i) Open Access}

\begin{abstract}
Objective: To investigate the changes of related immune cytokines (Dendritic Cells (DC) cells, $\mathrm{CD}^{+}, \mathrm{CD}^{+}$, Th17, IgG, IgM, IgA) in patients with nonsmall cell lung cancer (NSCLC) before and after chemotherapy. Methods: Eighty-five NSCLC patients who were treated in the Oncology Department of the Affiliated Hospital of Chengde Medical College from December 2018 to February 2021 were selected as the research objects, and the patients were analyzed at different time points (before chemotherapy, after the first chemotherapy, and after the second chemotherapy) Changes in the expression levels of DC cells, $\mathrm{CD}^{+}, \mathrm{CD}^{+}$, Th17, IgG, IgM, IgA in peripheral blood, and explore their correlation. Results: Before chemotherapy, after the first chemotherapy, and after the second chemotherapy, the peripheral blood $\mathrm{CD} 4^{+}$ and $\mathrm{CD}^{+}$were significantly increased, and the Th17, IgG, IgM, and IgA levels gradually decreased. The difference was statistically significant. But there was no obvious change in DC cells. Conclusion: There is no significant change in DC cells in peripheral blood of NSCLC patients before and after chemotherapy. $\mathrm{CD}^{+}$and $\mathrm{CD}^{+}$are significantly increased, Th17, IgG, IgM, and IgA levels are all decreased, which is a manifestation of impaired immune function of patients after chemotherapy.
\end{abstract}

\section{Keywords}

Non-Small Cell Lung Cancer, Chemotherapy, Immune-Related Factors

\section{Introduction}

Lung cancer currently accounts for the first place in the incidence and mortality 
of malignant tumors among adults in my country [1]. NSCLC as the main type of lung cancer, has a 5 -year survival rate of only $15 \%$, while the 5 -year survival rate of patients with clinical stage I is as high as $80 \%$ to $90 \%$ [2]. Therefore, early diagnosis and treatment are an important part of improving the prognosis of patients. However, the early stage of NSCLC has no obvious clinical symptoms. Most patients are in the advanced stage of the disease at the time of diagnosis, and have lost the opportunity for surgical treatment. They can only use radiotherapy, chemotherapy, and targeted therapy. Targeted therapy is generally only suitable for patients with sensitive gene mutations [3], and the indications for radiotherapy are also relatively limited [4], so chemotherapy is still the main treatment method, and it plays an important role in controlling disease progression and prolonging survival. However, the side effects of chemotherapy are large, which reduces the patient's quality of life. How to reduce the side effects of chemotherapy and improve its anti-tumor effect is a hot topic of research in recent years. The proposal and gradual application of immunotherapy have brought some optimistic changes to the treatment of tumors. Immunotherapy mainly works by stimulating the immune factors in the human body. In order to explore the relationship between chemotherapy and various immune factors as well as various immune factors, we conducted this study and look forward to helping patients.

\section{Objects and Methods}

\subsection{Research Objects}

A total of 85 NSCLC patients who were treated in the Oncology Department of the Affiliated Hospital of Chengde Medical College from December 2018 to February 2021 were selected as the research objects. There were 48 males and 37 females. The age ranged from 30 to 78 years old, with an average age (62.21 \pm $6.15)$ years old. There were 22 cases of lung squamous cell carcinoma, 57 cases of lung adenocarcinoma, and 6 cases of lung adenosquamous carcinoma. TNM staging: 23 cases in stage III and 62 cases in stage IV. Inclusion criteria: 1) NSCLC at the first visit and confirmed by histopathology, TNM staging is based on the AJCC staging standard (8th edition) [5]; 2) Age 18 to 80 years; 3) Pathology and imaging there is no indication for surgery in the scientific assessment; 4) KPS score $\geq 60$ points; 5) The expected survival time is more than 3 months. Exclusion criteria: 1) Patients with surgical indications requiring surgery. 2) Patients with severe heart, lung, liver, kidney and other vital organ dysfunctions who cannot tolerate chemotherapy.

\subsection{Chemotherapy}

The chemotherapy regimen is cisplatin/carboplatin + pemetrexed/gemcitabine/ paclitaxel. Dosage: pemetrexed $500 \mathrm{mg} / \mathrm{m}^{2}$, gemcitabine $1250 \mathrm{mg} / \mathrm{m}^{2}$, paclitaxel $175-200 \mathrm{mg} / \mathrm{m}^{2}$, cisplatin $75 \mathrm{mg} / \mathrm{m}^{2}$, carboplatin $\mathrm{AUC}=6$, intravenous drip administration, 21 days as a cycle. 


\subsection{Research Methods}

All patients were drawn with $10 \mathrm{ml}$ of fasting venous blood in the morning before chemotherapy (T1), on the 21st day after the first chemotherapy (T2), and on the 21st day after the second chemotherapy (T3). Separate the core for 20 minutes (centrifugation radius $14 \mathrm{~cm}$ ), take the supernatant and place it in a refrigerator at $-80^{\circ} \mathrm{C}$ for later use. The enzyme-linked immunosorbent assay was used to detect the levels of DC cells, $\mathrm{CD} 4^{+}, \mathrm{CD} 8^{+}, \mathrm{Th} 17, \operatorname{IgG}, \operatorname{IgM}$, and IgA in the serum. Each factor detection kit was purchased from Kangtai Heyuan Biotechnology Co, Ltd. (Beijing).

\subsection{Statistical Analysis}

The data analysis of this study was carried out using SPSS 22.0. Measurement data conformed to a normal distribution and expressed as mean \pm standard deviation, using $\mathrm{t}$ test, measurement data using $\chi^{2}$ test, and Pearson correlation analysis of the correlation between DC cells and $\mathrm{CD} 4^{+}, \mathrm{CD}^{+}, \mathrm{Th} 17, \mathrm{IgG}, \mathrm{IgM}$, IgA at each time point. All $\mathrm{P}$ values are two-sided tests, and $\mathrm{P}<0.05$ indicates that the difference is statistically significant.

\section{Results}

1) The patient's general information, including age, gender, pathological type, and TNM staging are comparable. See Table 1 for details.

2) $\mathrm{CD}^{+}$and $\mathrm{CD} 8^{+}$were significantly increased before chemotherapy, after 1 cycle of chemotherapy, and after 2 cycles of chemotherapy, Th17, IgG, IgM, and IgA levels gradually decreased, and each factor was significantly different at different time points $(\mathrm{P}<0.05)$. See Table 2 for details.

3) Pearson correlation analysis showed that: at different time nodes (before chemotherapy, after the first chemotherapy, after the second chemotherapy), the peripheral blood DC cells of patients had no correlation with other factors. See Table 3 for details.

\section{Discussion}

For patients with advanced lung cancer, chemotherapy is one of the most commonly used treatment methods [6]. The chemotherapy regimen containing cisplatin is the first-line chemotherapy regimen for advanced lung cancer, but after its treatment, there will be more serious complications due to its side effects, which affects the quality of life and limits its clinical application to a certain extent [7]. Nowadays, the development of tumor science is gradually developing

Table 1. Basic clinical data of patients.

\begin{tabular}{cccc}
\hline age & $\begin{array}{c}\text { Gender } \\
(\text { Male/Female })\end{array}$ & $\begin{array}{c}\text { Pathological type } \\
\text { (squamous cell carcinoma/adenocarcinoma/ } \\
\text { adenosquamous carcinoma) }\end{array}$ & $\begin{array}{c}\text { Stage } \\
\text { (III/IV) }\end{array}$ \\
\hline $62.21 \pm 6.15$ & $48 / 37$ & $22 / 57 / 6$ & $23 / 62$ \\
\hline
\end{tabular}


Table 2. Changes in the levels of peripheral blood DC cells, CD4 ${ }^{+}, \mathrm{CD}^{+}$, Th17, IgG, IgM, IgA over time.

\begin{tabular}{cccccccc}
\hline parameter & $\begin{array}{c}\text { DC } \\
\text { cells }\end{array}$ & $\begin{array}{c}\mathrm{CD}^{+} \\
(\%)\end{array}$ & $\begin{array}{c}\mathrm{CD}^{+} \\
(\%)\end{array}$ & Th17 & IgG & IgM & IgA \\
\hline & 1.57 & 27.32 & 26.23 & 3.42 & 12.31 & 1.53 & 1.62 \\
T1 & \pm & \pm & \pm & \pm & \pm & \pm & \pm \\
& 0.219 & 2.02 & 2.21 & 0.26 & 1.12 & 0.21 & 0.14 \\
& 1.50 & 29.18 & 31.89 & 3.28 & 11.01 & 1.25 & 1.16 \\
T2 & \pm & \pm & \pm & \pm & \pm & \pm & \pm \\
& 0.225 & 2.57 & 3.48 & 0.17 & 1.02 & 0.12 & 0.11 \\
& 1.53 & 33.98 & 33.34 & 2.53 & 10.58 & 0.98 & 0.97 \\
T3 & \pm & \pm & \pm & \pm & \pm & \pm & \pm \\
& 0.231 & 2.71 & 4.04 & 0.29 & 1.25 & 0.14 & 0.12 \\
P value & 0.405 & $<0.001$ & $<0.001$ & $<0.001$ & $<0.001$ & $<0.001$ & $<0.001$ \\
Comparison within & & & & & & & \\
the group (P value) & & & & & & & \\
T1 vs. T2 & 0.252 & $<0.001$ & $<0.001$ & $<0.001$ & $<0.001$ & $<0.001$ & $<0.001$ \\
T1 vs. T3 & 0.600 & $<0.001$ & $<0.001$ & $<0.001$ & $<0.001$ & $<0.001$ & $<0.001$ \\
T2 vs. T3 & 0.375 & $<0.001$ & $<0.001$ & 0.006 & $<0.001$ & $<0.001$ & $<0.001$ \\
\hline
\end{tabular}

Table 3. Correlation between DC cells and various factors at each time node.

\begin{tabular}{ccccccc}
\hline \multirow{2}{*}{ parameter } & \multicolumn{2}{c}{ DC cells (T1) } & \multicolumn{2}{c}{ DC cells (T2) } & \multicolumn{2}{c}{ DC cells (T3) } \\
\cline { 2 - 7 } & $\mathrm{r}$ & $\mathrm{P}$ & $\mathrm{r}$ & $\mathrm{P}$ & $\mathrm{r}$ & $\mathrm{P}$ \\
\hline $\mathrm{CD}^{+}(\%)$ & -0.036 & 0.754 & 0.039 & 0.773 & -0.254 & 0.094 \\
$\mathrm{CD} 8^{+}(\%)$ & 0.067 & 0.7 & -0.001 & 0.992 & 0.278 & 0.066 \\
$\mathrm{Th} 17$ & 0.105 & 0.437 & -0.083 & 0.529 & 0.035 & 0.715 \\
$\mathrm{IgG}$ & 0.099 & 0.505 & 0.177 & 0.228 & -0.084 & 0.562 \\
$\operatorname{IgM}$ & 0.078 & 0.412 & 0.045 & 0.315 & 0.097 & 0.213 \\
$\operatorname{IgA}$ & 0.101 & 0.395 & 0.056 & 0.574 & 0.045 & 0.075 \\
\hline
\end{tabular}

towards the internal environment and human autoimmunity, and how to stimulate the human body environment and autoimmunity in the process of anti-tumor treatment is particularly important [8] [9].

At present, immunotherapy has become a new treatment method for tumors. [10] [11] [12] Compared with chemotherapy, immunotherapy has stronger specificity and fewer side effects, and it also has a corresponding impact on the quality of life of patients. Decrease, so the research of immunotherapy has attracted much attention. Due to the extensive targeting of chemotherapy, it kills tumor cells and also destroys the body's own immune system. The impact of different immune factors is unknown. When chemotherapy and immunotherapy work together, the human body has a synergistic or antagonistic effect, or dif- 
ferent timings have different coordination effects. The optimal timing of combination therapy is unclear [13] [14]. Therefore, it is of great significance to study the changes of various immune factors before and after chemotherapy and their correlation.

DC cells are the most popular antigen-presenting cells in recent years. With the deepening of research, it has been discovered that cells are the most powerful antigen-presenting cells in the human body. A large number of studies have shown that [15] [16], DC cells play an irreplaceable role in the body's immune response, so anti-tumor research is also closely related to DC cells.

Cellular immunity is considered to be an important mechanism of the body's anti-tumor [17], and the cells that exert immune effects are mainly $\mathrm{T}$ lymphocytes. $\mathrm{T}$ lymphocyte subsets include $\mathrm{CD} 4^{+}$helper $\mathrm{T}$ cells and $\mathrm{CD} 8^{+}$suppressor $\mathrm{T}$ cells. $\mathrm{CD}^{+}$cells assist cellular immune response and humoral immunity. CD8 ${ }^{+}$ cells mainly inhibit the synthesis and secretion of antibodies and $\mathrm{T}$ cell proliferation. The relative distribution of $\mathrm{CD}^{+}$and $\mathrm{CD}^{+}$cells reflects the body Anti-tumor immune status.

Humoral immunity is an important line of defense for the body's immunity. IgM, IgA, and IgG constitute the main antibodies of humoral immunity, which were once studied abroad as indicators for judging prognosis [18]. Th17 plays an important role in tumor immunity and can help tumor cells achieve immune escape and immune tolerance, so as not to be eliminated by the body's immune system [19].

Our research found that in the course of chemotherapy, as the cycle of chemotherapy increases, there is no significant change in DC cells in the peripheral blood. $\mathrm{CD}^{+}$and $\mathrm{CD} 8^{+}$are significantly increased, and Th17, IgG, IgM, and IgA levels are all decreased, which may be one of the mechanisms by which the patient's immune function is suppressed. Therefore, it is very necessary to improve the body's immunity and increase immunotherapy in the early stage of chemotherapy. At the same time, the mechanism by which DC cells are not affected is still unclear and needs to continue to be studied, but it is not excluded that DC cells participate in tumor-related pathways and are continuously activated by tumor-related factors without being affected by chemotherapy. If DC cells can be found to participate in tumor response targets, there may be better anti-tumor therapies. At the same time, there is no correlation between DC cells and other factors, and further research is needed to prove that, after all, the human body is the product of a variety of internal environmental chemical reactions, and a single non-correlation does not mean that it is absolutely irrelevant. This study needs to continue to expand the sample size and extend the research period to further confirm this conclusion.

\section{Conclusion}

There was no significant change in DC cells in peripheral blood of NSCLC patients before and after chemotherapy. $\mathrm{CD} 4^{+}$and $\mathrm{CD} 8^{+}$were significantly in- 
creased, Th17, IgG, IgM, and IgA levels were all decreased. DC cells were not related to other factors, which may be the patient's immune function One of the frustrating mechanisms.

\section{Fund}

S \& T Program of Chengde (201804A030).

\section{Conflicts of Interest}

The authors declare no conflicts of interest regarding the publication of this paper.

\section{References}

[1] Wang, N., Mengersen, K., Tong, S., et al. (2019) Lung Cancer Mortality in China: Spatial and Temporal Trends Among Subpopulations. Chest, 156, 972-983.

[2] Li, L. and Li, M. (2019) Progress in Diagnosis and Treatment of Stage IA Lung Cancer. Chinese Journal of Practical Internal Medicine, 39, 420-424.

[3] Deng, T., Tang, J., Zhou, L., et al. (2019) Effective Targeted Therapy Based on Dynamic Monitoring of Gene Mutations in Non-Small Cell Lung Cancer. Translational Lung Cancer Research, 8, 532-538.

[4] Zeng, W.Q., Feng, W., Xie, L., et al. (2019) Postoperative Radiotherapy for Resected Stage IIIA-N2 Non-Small-Cell LUNG Cancer: A Population-Based Time-Trend Study. Lung, 197, 741-751. https://doi.org/10.1007/s00408-019-00284-7

[5] Li, H. (2017) Thoughts from Reading the Eighth Edition of the AJCC Lung Cancer Staging System. Chinese Journal of Surgery, 55, 346-350.

[6] Wang, Q.M. (2017) New Perspectives and New Thinking on Lung Cancer Chemotherapy under the Background of Precision Medicine. Journal of Medical Postgraduates, 30, 1151-1154.

[7] Fan, G.H., Xu, X.X., Chen, Y., et al. (2016) A Comparative Study of Transcutaneous Electrical Nerve Stimulation and Acupoint Pressing Combined with Moxibustion on Reducing Gastrointestinal Reactions in Patients with Lung Cancer after Chemotherapy with Cisplatin Regimen. Chinese Journal of Lung Diseases (Electronic Edition), 6, 41-45.

[8] Riley, R.S., June, C.H., Langer, R., et al. (2019) Delivery Technologies for Cancer Immunotherapy. Nature Reviews Drug Discovery, 18, 175-196. https://doi.org/10.1038/s41573-018-0006-Z

[9] Ribas, A. and Wolchok, J.D. (2018) Cancer Immunotherapy Using Checkpoint Blockade. Science, 359, 1350-1355. https://doi.org/10.1126/science.aar4060

[10] Nam, J., Son, S., Park, K.S., et al. (2019) Cancer Nanomedicine for Combination Cancer Immunotherapy. Nature Reviews Materials, 4, 398-414. https://doi.org/10.1038/s41578-019-0108-1

[11] Leone, R.D. and Emens, L.A. (2018) Targeting Adenosine for Cancer Immunotherapy. Journal for Immunotherapy of Cancer, 6, 1-9.

[12] Sahin, U. and Türeci, Ö. (2018) Personalized Vaccines for Cancer Immunotherapy. Science, 359, 1355-1360.

[13] Hegde, P.S. and Chen, D.S. (2020) Top 10 Challenges in Cancer Immunotherapy. Immunity, 52, 17-35. 
[14] Goldberg, M.S. (2019) Improving Cancer Immunotherapy through Nanotechnology. Nature Reviews Cancer, 19, 587-602.

[15] Sayed, M.A., Ahmed, M., Elsheikh, M.G., et al. (2016) PWM Control Techniques for Single-Phase Multilevel Inverter Based Controlled DC Cells. Journal of Power Electronics, 16, 498-511. https://doi.org/10.6113/JPE.2016.16.2.498

[16] Yang, G., Jiang, Y., Tong, P., et al. (2017) Alleviation of Enterotoxigenic Escherichia coli Challenge by Recombinant Lactobacillus plantarum Expressing a FaeG- and DC-Targeting Peptide Fusion Protein. Beneficial Microbes, 8, 379-391. https://doi.org/10.3920/BM2016.0116

[17] Zhang, L.J., Zhong, J.S., Zhong, H.X., et al. (2015) Clinical Significance of Peripheral Blood Lymphocyte Immunophenotype Detection in Patients with Malignant Tumors. International Journal of Laboratory Medicine, 36, 3565-3567.

[18] Fallon, E.M., Le, H.D. and Puder, M. (2010) Prevention of Parenteral NutritionAssociated Liver Disease: Role of $\omega$-3 Fish Oil. Current Opinion in Organ Transplantation, 15, 334-340. https://doi.org/10.1097/MOT.0b013e3283394879

[19] Jia, H.M., Fang, X.Z., Zhang, G.Q., et al. (2012) The Expression of Interleukin 17 and Foxp3 in Stage IIIA Lung Squamous Cell Carcinoma and Adenocarcinoma and Their Relationship with Prognosis. Chinese General Practice, 15, 1345-1349. 